\title{
Repair of critical size defects in the rat cranium using ceramic-reinforced PLA scaffolds obtained by supercritical gas foaming
}

\author{
Marc-Olivier Montjovent, ${ }^{1}$ Laurence Mathieu, ${ }^{2}$ Hugo Schmoekel, ${ }^{3,4}$ Silke Mark, ${ }^{5}$ \\ Pierre-Etienne Bourban, ${ }^{2}$ Pierre-Yves Zambelli, ${ }^{6}$ Lee Ann Laurent-Applegate, ${ }^{7}$ Dominique P. Pioletti ${ }^{1}$ \\ ${ }^{1}$ Laboratoire de Biomécanique en Orthopédie EPFL-HOSR, Ecole Polytechnique Fédérale de Lausanne, \\ CH-1015 Lausanne, Switzerland \\ ${ }^{2}$ Laboratoire de Technologie des Composites et Polymères, Ecole Polytechnique Fédérale de Lausanne, \\ CH-1015 Lausanne, Switzerland \\ ${ }^{3}$ Laboratoire de Médecine Régénérative et de Pharmacobiologie, Ecole Polytechnique Fédérale de Lausanne, \\ CH-1015 Lausanne, Switzerland \\ ${ }^{4}$ Poliklinik für Kleine Haustiere der Universität Berlin, D-14163, Germany \\ ${ }^{5}$ Ludwig Institute for Cancer Research, Molecular Immunology Group, Lausanne Branch, University of Lausanne, \\ Epalinges, Switzerland \\ ${ }^{6}$ Hôpital Orthopédique de la Suisse Romande, CH-1005 Lausanne, Switzerland \\ ${ }^{7}$ Unité de Thérapie Cellulaire en Orthopédie, Centre Hospitalier Universitaire Vaudois, CH-1011 Lausanne, Switzerland
}

Received 27 July 2006; revised 10 October 2006; accepted 3 November 2006

Published online 21 March 2007 in Wiley InterScience (www.interscience.wiley.com). DOI: 10.1002/jbm.a.31208

\begin{abstract}
Bioresorbable scaffolds made of poly(L-lactic acid) (PLA) obtained by supercritical gas foaming were recently described as suitable for tissue engineering, portraying biocompatibility with primary osteoblasts in vitro and interesting mechanical properties when reinforced with ceramics. The behavior of such constructs remained to be evaluated in vivo and therefore the present study was undertaken to compare different PLA/ceramic composite scaffolds obtained by supercritical gas foaming in a critical size defect craniotomy model in Sprague-Dawley rats. The host-tissue reaction to the implants was evaluated semiquantitatively and similar tendencies were noted for all graft substitutes: initially highly
\end{abstract}

reactive but decreasing with time implanted. Complete bonebridging was observed 18 weeks after implantation with PLA/ 5 wt \% $\beta$-TCP (PLA/TCP) and PLA/5 wt \% HA (PLA/HA) scaffolds as assessed by histology and radiography. We show here for the first time that this solvent-free technique provides a promising approach in tissue engineering demonstrating both the biocompatibility and osteoconductivity of the processed structures in vivo. (c) 2007 Wiley Periodicals, Inc. J Biomed Mater Res 83A: 41-51, 2007

Key words: bone tissue engineering; biomaterials; biocompatibility; scaffold; polylactic acid

\section{INTRODUCTION}

Ceramic-reinforced poly(L-lactic acid) (PLA) structures obtained by melt-extrusion followed by supercritical gas foaming offer suitable conditions for primary human fetal osteoblasts to achieve a full differentiation process in vitro. ${ }^{1}$ Therefore, it was of

Correspondence to: D. P. Pioletti; e-mail: dominique. pioletti@epfl.ch

Contract grant sponsor: Swiss National Science Foundation; contract grant numbers: PNR 46 No. 404640-101114/1, FNRS No. 2100-066872.04.01

Contract grant sponsors: Fondation Lémanique pour la Recherche sur le Tissu Osseux, Lausanne Center for Bone Tissue Engineering

(C) 2007 Wiley Periodicals, Inc. interest to look at in vivo host-tissue induced reactions as well as the potential for osteoconductive properties of these biomaterials. As maxillofacial bone repair is one of the targeted applications for the implants described here, they were tested preclinically in a cranial model.

The critical size defect model (CSD) is often used to study orthopaedic materials. ${ }^{2}$ It has been defined as the smallest in situ bone defect that could not heal spontaneously by bone formation during the lifespan of the animal. ${ }^{3}$ The CSD created on the bony vault of the cranium (calvaria) represents a severe test for bone graft substitutes. ${ }^{3}$ Compared with long bones, the skull is biologically rather inert due to a poor blood supply and a relative deficiency of bone marrow. ${ }^{4}$ CSDs in the calvaria have been established for different animal species. ${ }^{4-20}$ The rat calvarial 
model offers advantages: the parietal bone is a large plate that facilitates the operation and the analysis (histology, imaging), no implant fixation is required, and the costs are limited in comparison with large animal models. Furthermore, as this experimental approach is widely used, a precise comparison of different grafted materials is possible. ${ }^{21}$ Modeling on parietal bone has been applied to rats from different strains and at various ages. ${ }^{7-9,22,23}$ The SpragueDawley rats used herein did not spontaneously fill $8 \mathrm{~mm}$ diameter full thickness defects 12 -weeks postsurgery. ${ }^{24}$

Different types of bone graft substitutes can be used to fill a CSD. Among them, synthetic substitutes are generally made of ceramics, such as calcium phosphate, or polymers, such as collagen or poly $(\alpha-$ hydroxy acids). However, ceramics tend to be too brittle and polymers too soft. Working with polymerbased composites offers a wider range of mechanical properties closer to bone, osteocondution induced by ceramics and a better control of resorption rate. ${ }^{25-27}$ Polymer-based foams can be processed in different ways: solvent casting/particulate leaching, ${ }^{28,29}$ thermally induced phase separation, or emulsion freezedrying, ${ }^{30-33}$ gas foaming. ${ }^{34-36}$ The latter technique has the main advantage of avoiding the use of potentially toxic organic solvents. ${ }^{37}$ Gas foaming is based on the use of a gas porogen, and can be decomposed into several steps: gas dissolution, bubble nucleation, growth, and stabilization. Every step affects final foam morphology: controlling saturation pressure monitors gas concentration in the polymer and therefore porosity volume. The rate of pressure release influences pore nucleation density; the rate of temperature decrease governs pore growth, therefore pore diameter and interconnections. Use of supercritical $\mathrm{CO}_{2}$ allows the incorporation of biological agents and ceramic particles, and the manufacture of open pore foams with low intrinsic viscosity amorphous PLGA (polylactic-co-glycolic acid). ${ }^{38-40}$ In this study we focused on semicrystalline PLA, which allowed us obtaining open pore scaffolds with controlled porosity and morphology and improved mechanical properties, thus creating for bone cells an environment similar to natural bone.

Therefore, PLA/5 wt \% $\beta$-TCP (PLA/TCP) and PLA/5 wt \% HA (PLA/HA) implants were tested in the Sprague-Dawley CSD craniotomy model to determine their interactions with host tissues and their osteoconductive abilities. Comparison was extended to $\beta$-tricalcium phosphate matrix (hereafter designated as $\beta$-TCP Mathys), with the same composition and structure like chronOS ${ }^{\mathrm{TM}}$ scaffolds already used in clinical applications (Synthes, Bettlach, Switzerland). We demonstrate here, for the first time, the high osteoconductive potential of PLA/ceramic composite structures processed by supercritical gas foaming. Thus, this original approach is undoubtedly promising for bone tissue engineering.

\section{MATERIALS AND METHODS}

\section{Animals and housing}

All animal experiments were performed with the approval of the Veterinary Authority from the Canton of Vaud (authorization No. 1777). Sprague-Dawley albino rats (females, 84-92 days old, 275-300 g) were purchased from Iffa Credo (Charles River Laboratories, L'Arbresle Cedex, France) and acclimated for 14 days prior to surgery. Animals were grouped by 3 on wood-based litters in PET cages $\left(405 \times 255 \times 197 \mathrm{~mm}^{3}\right)$ equipped with Reemay filter covers (No. E4FVCOU910, Charles River Laboratories, L'Arbresle Cedex, France). Strictly controlled breeding conditions were used: temperature: $(22 \pm 2)^{\circ} \mathrm{C}$, relative humidity: $(55 \pm 10) \%$, light/dark hours schedule : 12/12. They were fed a balanced solid diet (Mouse/Rat - complete feed extrudate 3436, Provimi Kibla AG, Switzerland) with food and water provided ad libitum during the experiment. Individual body weights were recorded prior to implantation and thereafter on a weekly basis.

\section{Scaffold generation}

Processing of the foams, and analyses of the scaffold morphology and properties were published in details elsewhere. ${ }^{41}$ A PLA (Boehringher Ingelheim, Germany) and two ceramic powders, hydroxyapatite (HA) (Merck KGaA, Darmstadt, Germany) and $\beta$-tricalcium phosphate ( $\beta$-TCP) (Fluka, Buchs SG, Switzerland), were included in this study. The batch of HA (nano) powder used hereafter was recently described. ${ }^{42}$ Its purity was verified by X-ray diffraction (XRD) and its size assessed by measuring its specific surface area (SSA) that was $62.53 \mathrm{~m}^{2} / \mathrm{g}$ (standard deviation (SD) $=0.20 \mathrm{~m}^{2} / \mathrm{g}$ ). The $\beta$-TCP (micro) powder was usually shown by XRD to contain small amounts of $\beta$ calcium pyrophosphate $(\beta-\mathrm{CPP}, \max <10 \%)$. A representative measured SSA for this powder was $1.10 \mathrm{~m}^{2} / \mathrm{g}$ (SD = $0.01 \mathrm{~m}^{2} / \mathrm{g}$ ). Scaffolds were generated as following: after drying, PLA pellets and ceramic particles (5 wt \%) were mixed, and further melt-extruded in order to obtain cohesive composite preforms. Mixing parameters of the microcompounder (Micro 5, DSM, The Netherlands) were set at a temperature of $205^{\circ} \mathrm{C}$, a screw rotation speed of $100 \mathrm{rpm}$, and a residence time of $4 \mathrm{~min} .{ }^{43}$ Foaming was then carried out using supercritical $\mathrm{CO}_{2}$ (pure $>99.995 \%$; SL Gas, Switzerland) in a custom made high-pressure chamber (Autoclave France, France), equipped with a computerized data acquisition system. After polymer saturation with $\mathrm{CO}_{2}$, foaming was achieved by sudden gas release and the porous structure frozen by simultaneous cooling. Initial depressurization rate controlled by a back-pressure regulator, and maximum cooling rate are significant parameters that affect pore growth and stabilization. PLA/TCP and PLA/HA scaffolds tested in vivo in this preliminary study 

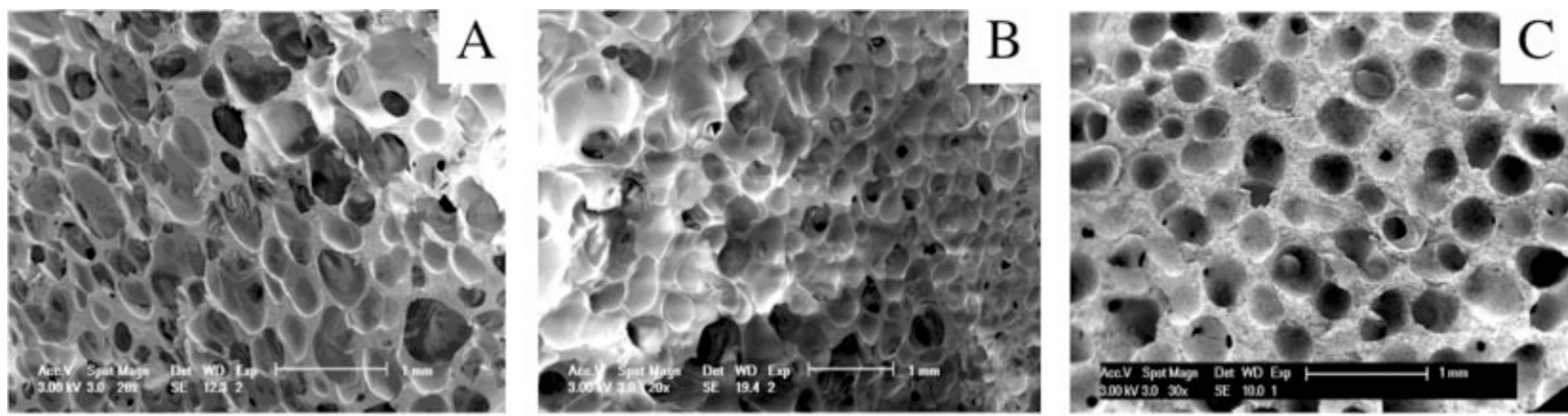

Figure 1. Scanning electron micrographs of scaffold structures. (A) PLA 5\% $\beta$-TCP: porosity $(83.4 \pm 2.5) \%$, pore diameter: $390 \pm 180 \mu \mathrm{m}$, modulus: $121.0 \pm 12.1 \mathrm{MPa}$. (B) PLA 5\% HA: porosity $(79.2 \pm 0.9) \%$, pore diameter: $400 \pm 250 \mu \mathrm{m}$, modulus: $133.2 \pm 15.2 \mathrm{MPa}$. (C) $\beta$-TCP Mathys: porosity $(75.4 \pm 0.3) \%$, pore diameter: $410 \pm 30 \mu \mathrm{m}$, modulus: $2.70 \pm 0.44 \mathrm{GPa}$.

were processed using the following parameters: $4.5 \mathrm{bar} / \mathrm{s}$ and $4.4^{\circ} \mathrm{C} / \mathrm{s}$.

In parallel, ChronOS ${ }^{\mathrm{TM}}$ scaffolds ( $\beta$-TCP Mathys), made of $\beta$-TCP, were tested (Mathys, Bettlach, Switzerland) and scaffold morphology was evaluated by scanning electron microscopy: porosity, pore size, anisotropy, and ceramic distribution were verified (Fig. 1). Implanted volumes were machined into cylinders $(3 \mathrm{~mm}$ high, $8 \mathrm{~mm}$ diameter), and sterilized by gamma irradiation ( $25 \mathrm{kGy}$ ).

\section{Rat calvarial surgery}

Rats were anesthetized using $2-3.5 \%$ isoflurane in oxygen for $\sim 5 \mathrm{~min}$ in a small induction chamber using a VMS anesthesia machine (MDS Matrx, Orchard Park, NY). Once sedated, the animals were shaved and the cranial surface sterilely prepared with alcohol. The animals were placed on a heating pad to maintain body temperature during the procedure. A midline incision $(\sim 3 \mathrm{~cm}$ long) was made from the nasal bone to the crest using a surgical blade. The soft tissue and the periosteum were elevated. The craniotomy defect $(8 \mathrm{~mm})$ was created in the parietal bone with a trephine drill (No. 207421, Provet SA, Lyssach, Switzerland), under constant saline irrigation (Fig. 2) with extreme care to preserve the underlying dura (Fig. 3). The resulting defect was grafted with scaffolds made either of PLA/TCP, PLA/HA, or $\beta$-TCP Mathys. The skin was closed with stainless steel surgical clips. Postoperative analgesia was provided by subcutaneous injection of $0.03 \mathrm{~mL}$ Butorphanol Morphasol ${ }^{\circledR}$ (Dr. E. Gräub AG, Bern, Switzerland). Following 12 days or 18 weeks after surgery, animals were sacrificed by $\mathrm{CO}_{2}$ asphyxiation. Craniotomy sites with $5 \mathrm{~mm}$ neighboring bone were collected from the skull and placed in $40 \%$ ethanol. Aseptic surgical technique was used throughout the procedure, and each condition was tested in triplicates.

\section{Blood collection and leukocyte count}

Directly after animal sacrifice, blood samples were collected from heart puncture in EDTA-containing tubes (Milian SA, Plan-les-Ouates, Switzerland). Total leukocyte numbers were assessed using a counting chamber (Marienfeld $\mathrm{GmbH} \& \mathrm{Co}$. KG, Lauda-Koenigshofen, Germany), following hemolysis of red blood cells in Turk's solution $(0.01 \%$ crystal violet in $3 \%$ acetic acid). Differential counts of white blood cells including lymphocytes, monocytes, neutrophils, eosinophils, and basophils were determined
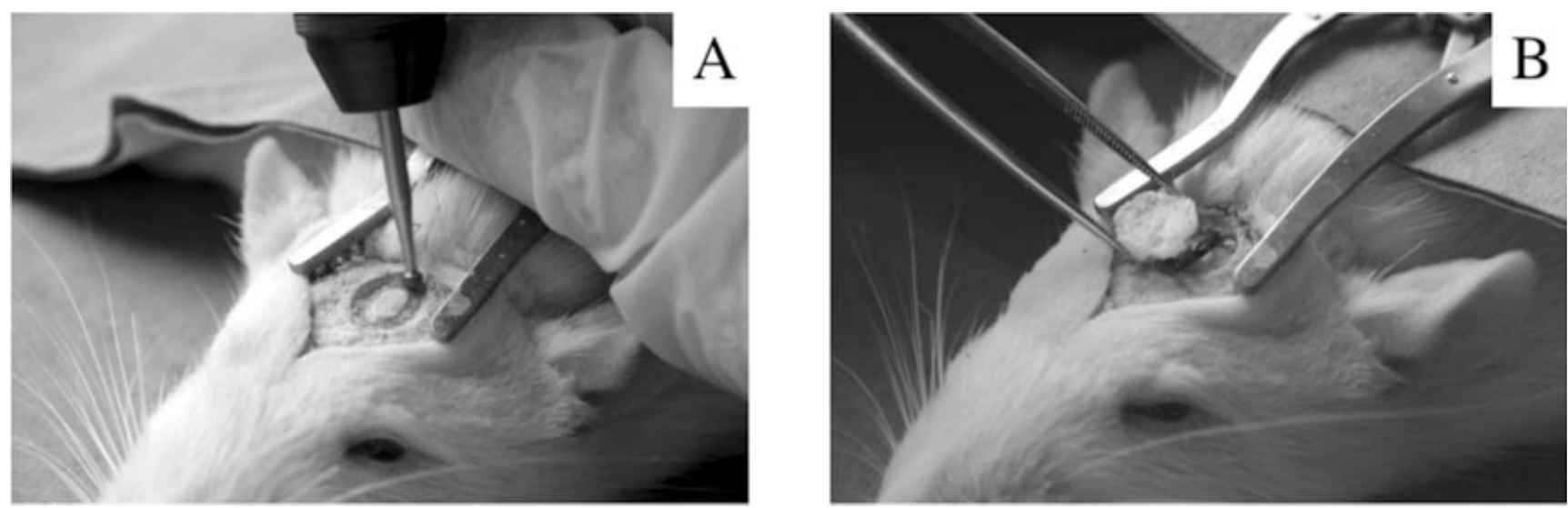

Figure 2. Skull surgery. (A) Perforation of the parietal bone using a surgical trephine drill. (B) Implantation of a circular bone substitute into the defect $(8 \mathrm{~mm}$ diameter). 


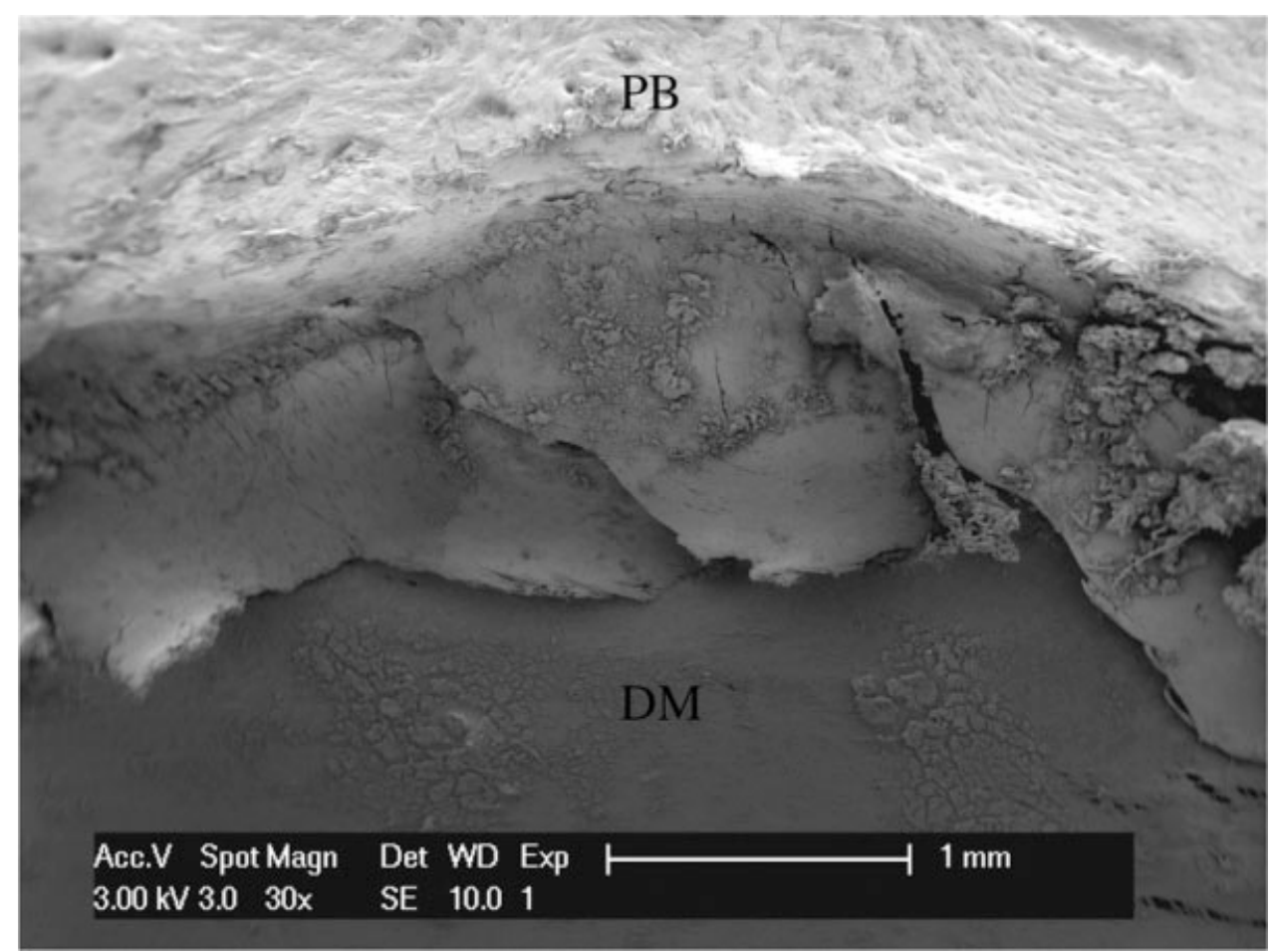

Figure 3. Scanning electron micrograph showing the parietal bone (PB) and the dura mater (DM) exposed after the surgical intervention. Scale bar: $1 \mathrm{~mm}$.

morphologically from blood smears stained with DiffQuick (Dade Behring AG, Düdingen, Switzerland), yielding results comparable with the Peppenheim technique.

\section{Quantification of secreted cytokines}

Plasma levels of proinflammatory cytokines IL6, TNF- $\alpha$, and IFN- $\gamma$ were measured using commercially available ELISA kits according to the manufacturer's instructions (BD Biosciences Pharmingen, San Diego, CA). Blood samples collected as described above were centrifuged for $10 \mathrm{~min}$ at $1000 \mathrm{~g}$ and plasma was stored at $-80^{\circ} \mathrm{C}$ until analyses. Measurements were made on $100 \mu \mathrm{L}$ in triplicate for each sample. Absorbance was recorded at $450 \mathrm{~nm}$ using a Wallac 1420 VICTOR $^{2}$ multilabel plate reader (Wallac Oy, Turku, Finland). The concentration of each cytokine was calculated with reference to a standard curve that was constructed using recombinant rat proteins provided in each kit.

\section{Histological evaluation}

After fixation in $10 \%$ buffered formalin, samples were decalcified in $14 \%$ EDTA ( $\mathrm{pH} 7.2$ ) for 2 weeks at $37^{\circ} \mathrm{C}$ and during this period the solution was changed one time. Specimens were then rinsed in PBS ( $\mathrm{pH} 7.4)$ containing $6.8 \%$ sucrose overnight at $4^{\circ} \mathrm{C}$, and dehydrated in $100 \%$ acetone during $60-90 \mathrm{~min}$ at $4^{\circ} \mathrm{C}$. Finally, they were embedded in 2-hydroxyethylmethacrylate using infiltration and embedding solutions (Technovit 8100, Heraus Kulzer $\mathrm{GmbH}$, Wehrheim, Germany). To evaluate the host tissue response around the implants and to visualize bone formation, three sections of $3 \mu \mathrm{m}$ thickness, and $1 \mathrm{~mm}$ distant from each other were prepared and stained with hematoxylin and eosin (H\&E by Gill). Sections were screened at low power $(40 \times)$ to determine the capsule thickness. Three measurements were taken on four sides of the scaffold (periosteal (upper)/cerebral (lower)/right/left). Cell counts

TABLE I

Scoring System for Host Tissue Reaction Evaluation

\begin{tabular}{|c|c|c|c|c|c|}
\hline \multicolumn{2}{|c|}{ Fibrous Capsule Thickness Charaterization } & \multicolumn{2}{|c|}{ Host Cellular Response } & \multicolumn{2}{|c|}{ Cell Type Repartition } \\
\hline Grade & Thickness Range $(\mu \mathrm{m})$ & Grade & $\begin{array}{l}\text { Cells Counted on Each } \\
\text { Fibrous Capsule Section }\end{array}$ & Grade & Range (\%) \\
\hline 0 & 0 & 0 & 0 & 0 & 0 \\
\hline $1+$ & $1-30$ & $1+$ & $1-60$ & $1+$ & $1-5$ \\
\hline $2+$ & $31-150$ & $2+$ & $61-300$ & $2+$ & $6-25$ \\
\hline $3+$ & $151-300$ & $3+$ & $301-600$ & $3+$ & $26-50$ \\
\hline $4+$ & $301-450$ & $4+$ & $601-900$ & $4+$ & $51-75$ \\
\hline $5+$ & $451-600$ & $5+$ & $901-1200$ & $5+$ & $76-100$ \\
\hline
\end{tabular}


within the fibrous tissue were assessed at high magnification $(400 \times)$. Three representative square sections of 0.250 $\mathrm{mm}$ side were analyzed on each border of the implant using an ocular grid. Different cells including neutrophils, foreign body giant cells (FBGC), lymphocytes, macrophages, and fibroblasts were determined morphologically. Mean values were calculated for each section and then for each implant. Tissue reaction was appraised by the method described by Black, ${ }^{44}$ and adapted from earlier studies. ${ }^{45-47}$ Briefly, capsular thickness, cellular response and cell type repartitions were evaluated, and scores from 0 to $5+$ were attributed according to the criteria given in Table I. An overall rating was obtained using weighting factors $(5 \times$ for the capsular thickness, $3 \times$ for the cellular response observed in the capsule, $5 \times$ for the neutrophils, $2 \times$ for the FBGCs, $1 \times$ for the lymphocytes, $1 \times$ for macrophages, and $1 \times$ for the fibroblasts). Reactions were classified into 6 categories, which were as follows: no reaction (0), minimal (1-10), slight (11-25), moderate (26-40), marked (41-60), and excessive $(>60)$.

\section{Scanning electron microscopy}

Samples were rinsed with PBS (Invitrogen, Carlsbad, CA) prior to fixation with primary glutaraldehyde fixative: $0.1 \mathrm{M}$ sodium cacodylate (Polysciences, Warrington, PA), $5 \%$ glutaraldehyde (Polysciences), $0.1 M$ sucrose (Axon Lab AG, Baden-Dätwill, Switzerland), $\mathrm{pH} 7.4$, for $45 \mathrm{~min}$ at $4{ }^{\circ} \mathrm{C}$. The fixative was then replaced by a buffered sucrose vehicle: $0.1 \mathrm{M}$ sodium cacodylate, $0.1 \mathrm{M}$ sucrose, $\mathrm{pH} 7.4$, for $30 \mathrm{~min}$ at $4^{\circ} \mathrm{C}$. After this step, bones were placed in osmium fixative: $0.1 \mathrm{M}$ sodium cacodylate, $0.1 \mathrm{M}$ sucrose, $1 \%$ osmium tetroxyde (Polysciences), $\mathrm{pH} \mathrm{7.4,} \mathrm{for} 60 \mathrm{~min}$ at $4{ }^{\circ} \mathrm{C}$. Samples were washed twice at room temperature with demineralized water before dehydration and air-drying from a solution of hexamethyldisilazane (Polysciences). The sample surfaces were gold-coated during 2 min under $1 \mathrm{kV}$ and observed using a scanning electron microscope Philips XL30 (FEI, Hillsboro, OR) at a voltage of $5 \mathrm{kV}$.

\section{Radiography of rat specimen}

The presence of newly formed bone was determined radiographically. Skulls were placed with the exocranial surfaces on top of a radiographic cassette (High Resolution Storage Phosphor Screen CR Cassette, Kodak, Rochester, $\mathrm{NY}$ ) at a standardized distance of $125 \mathrm{~cm}$ from the X-ray head $(10 \mathrm{mAs}, 50 \mathrm{kV})$. Samples were imaged and processed with image analysis software (ImageJ, Wayne Rasband, National Institutes of Health, Bethesda, MD). Histograms were identified on the digitized radiographs in each defect area after adjustment of the background to zero.

\section{Statistical analysis}

For this study, 24 animals were randomly assigned to the different groups, including the sham surgery rats and all conditions were tested in triplicate. Evaluations were performed in a blind manner when analyzing the treat-

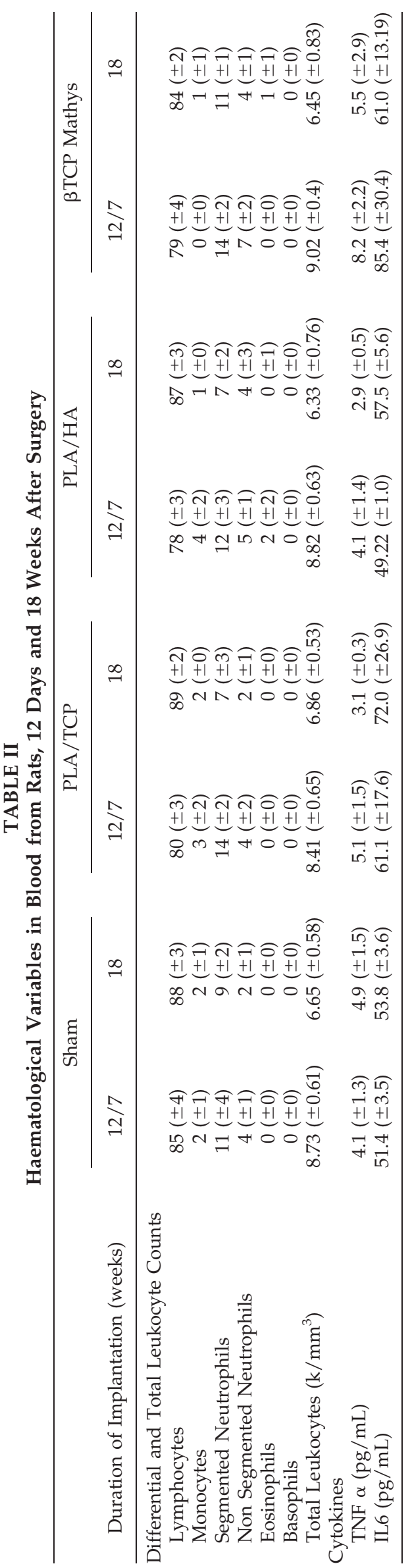


TABLE III

Histological Semiquantative Evaluation of Host Tissue Reaction

\begin{tabular}{|c|c|c|c|c|c|c|c|c|c|}
\hline \multirow[b]{2}{*}{ Group } & \multirow{2}{*}{$\begin{array}{c}\text { Time } \\
\text { (weeks) }\end{array}$} & \multirow{2}{*}{$\begin{array}{l}\text { Capsule } \\
\text { Thickness }\end{array}$} & \multirow{2}{*}{$\begin{array}{l}\text { Cellular } \\
\text { Response }\end{array}$} & \multicolumn{5}{|c|}{ Cells Present in the Fibrous Capsule } & \multirow{2}{*}{$\begin{array}{l}\text { Response } \\
\text { Evaluation }\end{array}$} \\
\hline & & & & Neutrophils & FBGC & Lymphocytes & Macrophages & Fibroblasts & \\
\hline \multirow[t]{6}{*}{ PLA/TCP } & $12 / 7$ & $3+$ & $5+$ & $2+$ & 0 & 0 & $1+$ & $4+$ & Marked $(45+)$ \\
\hline & $12 / 7$ & $4+$ & $5+$ & $2+$ & 0 & 0 & $2+$ & $4+$ & Marked $(51+)$ \\
\hline & $12 / 7$ & $4+$ & $4+$ & $2+$ & 0 & 0 & $2+$ & $5+$ & Marked $(49+)$ \\
\hline & 18 & $3+$ & $3+$ & $1+$ & 0 & $1+$ & $2+$ & $5+$ & Moderate $(37+)$ \\
\hline & 18 & $2+$ & $2+$ & 0 & 0 & 0 & $2+$ & $5+$ & Slight $(23+)$ \\
\hline & 18 & $3+$ & $3+$ & $1+$ & 0 & 0 & $2+$ & $5+$ & Moderate $(36+)$ \\
\hline \multirow[t]{6}{*}{ PLA/HA } & $12 / 7$ & $4+$ & $4+$ & $2+$ & 0 & 0 & $2+$ & $4+$ & Marked $(48+)$ \\
\hline & $12 / 7$ & $3+$ & $3+$ & $1+$ & 0 & 0 & $2+$ & $5+$ & Moderate $(36+)$ \\
\hline & $12 / 7$ & $4+$ & $4+$ & $1+$ & 0 & 0 & $3+$ & $4+$ & Marked $(44+)$ \\
\hline & 18 & $2+$ & $2+$ & 0 & 0 & 0 & $2+$ & $5+$ & Slight $(23+)$ \\
\hline & 18 & $3+$ & $3+$ & $1+$ & 0 & $1+$ & $2+$ & $4+$ & Moderate $(36+)$ \\
\hline & 18 & $4+$ & $2+$ & $1+$ & 0 & 0 & $2+$ & $5+$ & Moderate $(38+)$ \\
\hline \multirow[t]{6}{*}{$\beta$ TCP Mathys } & $12 / 7$ & $3+$ & $3+$ & $2+$ & $1+$ & 0 & $2+$ & $4+$ & Marked $(42+)$ \\
\hline & $12 / 7$ & $4+$ & $3+$ & $1+$ & $1+$ & 0 & $3+$ & $4+$ & Marked $(43+)$ \\
\hline & $12 / 7$ & $5+$ & $5+$ & $1+$ & 0 & 0 & $2+$ & $5+$ & Marked $(52+)$ \\
\hline & $18+$ & $4+$ & $4+$ & 0 & 0 & 0 & $2+$ & $5+$ & Moderate $(39+)$ \\
\hline & 18 & $3+$ & $4+$ & $1+$ & 0 & 0 & $2+$ & $5+$ & Moderate $(39+)$ \\
\hline & 18 & $5+$ & $4+$ & $2+$ & 0 & 0 & $2+$ & $5+$ & Marked $(54+)$ \\
\hline
\end{tabular}

ments of the defects. Results are presented as mean values with associated standard errors of the mean.

\section{RESULTS}

\section{Body weights}

The evolution of body weights was similar in all groups during this study (data not shown). The implants tested showed no effect on this variable, compared to the sham operated animals.

\section{Haematology}

Total and differential leukocyte cell counts were alike in all implanted groups at the two time points (12 days and 18 weeks after the surgery), and are summarized in Table II. No difference was noticed compared with the sham group. A slight decrease of leukocyte cell numbers was observed between day 12 and week 18 within each group. Systemic concentrations of proinflammatory cytokines IL6 and TNF$\alpha$ were measured and values are reported in Table II. During the experiment, plasma levels of these proteins remained stable and no marked variation between groups was observed, whereas IFN- $\gamma$ was not detectable.

\section{Histology}

Rating of the overall host tissue response of each scaffold is presented at both time points in Table III.
After 12 days in vivo, marked to moderate inflammatory responses were observed. This assessment was then attenuated with time of exposure with moderate to slight reactions noticed at week 18. In more detail at day 12, PLA/TCP implants were covered with a layer of approximately 2-3 cells in thickness (consisting predominantly of macrophages), and surrounded by loose connective tissue with an adjacent capillary network. PLA/HA composites induced a comparable host-tissue reaction, whereas superficial host-tissue infiltration was observed within $\beta$-TCP Mathys inserts [Fig. 4(A-C)]. Macrophages and multinucleated giant cells were seen in the proximity of the fragments coming from these scaffolds. The presence of particles detached from $\beta$-TCP Mathys implants was noticed along with FBGCs at a higher frequency within this group, compared to the PLA/ ceramic groups [Fig. 4(D-F)]. At this early time point, lamellar bone deposition was observed in all groups between the old bone and the dura mater, as well as around the trephine margins [Fig. 4(G-I)]. Active osteoblasts were present on the surface of the new bone matrix and within forming osteons. Only a few osteoclasts were located at this site of intense bone modeling. At the end of the study, the vault of the cranium was restored in one animal out of three within each of the PLA/TCP and PLA/HA groups (Fig. 5). Bone was formed predominantly at the cerebral (lower) side of the implants, but also on the lateral and periosteal (upper) sides. In the other animals from these treatment groups a clear reduction of the original defect size was detected. Albeit the healing process in $\beta$-TCP Mathys scaffolds was less 
PLA/TCP
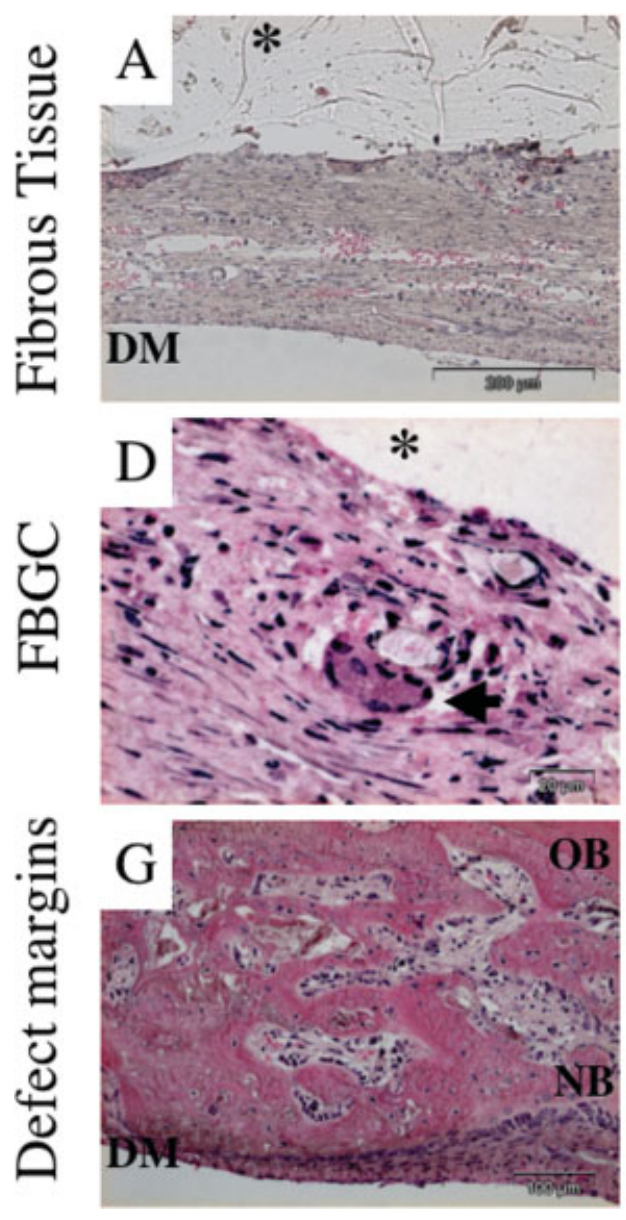

PLA/HA
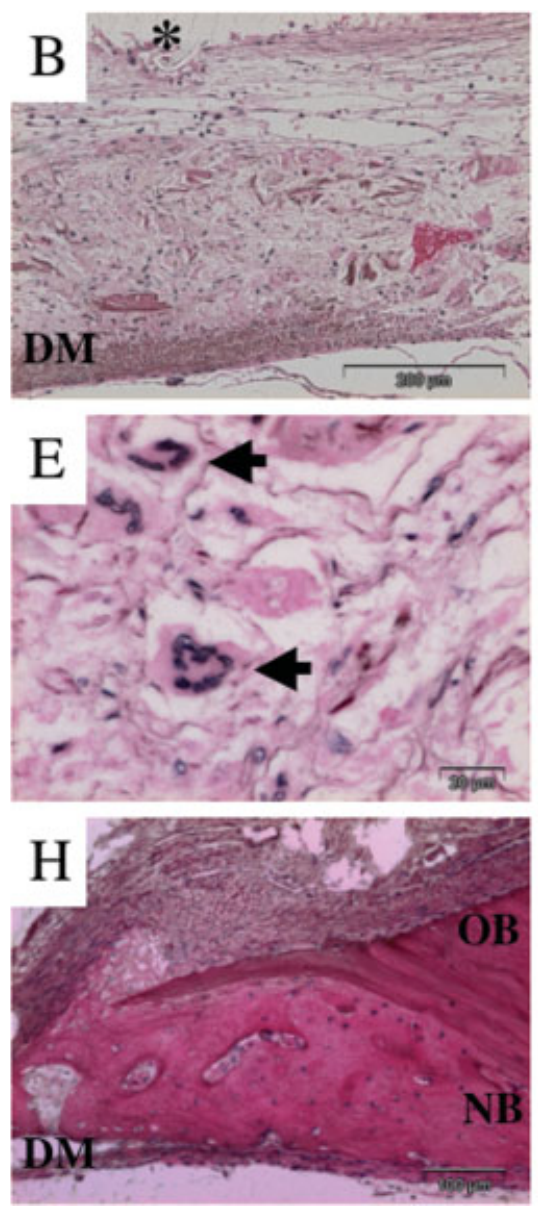

$\beta$ TCP Mathys
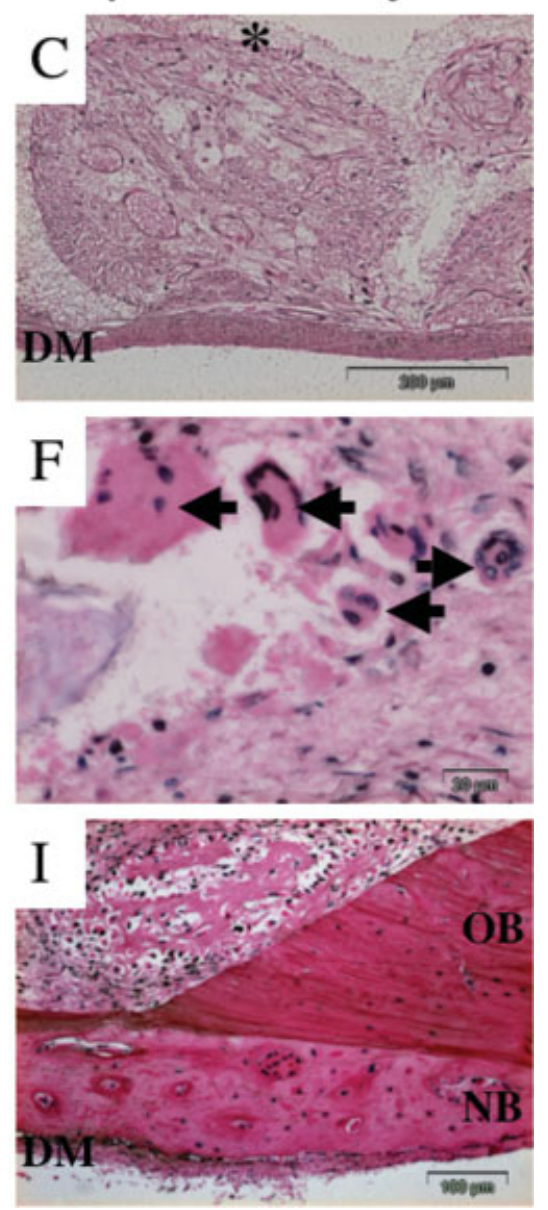

Figure 4. Photomicrographs of histological representative sections at 12 days after the implantation of PLA/TCP (right), PLA/HA (middle), and $\beta$-TCP Mathys (left). (A-C) Fibrous capsule. (D-F) Localization of foreign body giant cells. (G-I) Edge from the defect. Abbreviations and signs used: foreign body giant cells (FBGC) indicated with arrows; new bone (NB); old bone (OB); implant localization $\left(^{*}\right)$. Hematoxylin and eosin stain. Scale bars: (A-C) $200 \mu \mathrm{m},(\mathrm{D}-\mathrm{F}) 20 \mu \mathrm{m},(\mathrm{G}-\mathrm{I})$ $100 \mu \mathrm{m}$. [Color figure can be viewed in the online issue, which is available at www.interscience.wiley.com.]

advanced at this time point, ossification was observed in many pores of its structure. In the sham group, the cavity was mainly covered with fibrous tissue and bone formation occurring only along the defect margin and this is consistent with the model of CSD.

\section{Radiography of rat specimen}

In addition, the presence of newly formed bone was confirmed radiographically (Fig. 6). An increase in the area of radio-opacity representing new bone formation was observed within the skull defects between day 12 and week 18 for the PLA/TCP and PLA/HA implants. Because of the high radiopacity of the $\beta$-TCP Mathys scaffold, bone formation was not easily detected by $\mathrm{X}$-ray in this group, leading to a possible underestimation of the healing process, whereas no new bone formation occurred in the sham group.

\section{DISCUSSION}

The aim of this study was to test in vivo the biocompatibility and osteoconductivity of ceramic-reinforced PLA scaffolds obtained by supercritical gas foaming. The CSD craniotomy model was chosen for this purpose. A key finding was the observation of complete bone bridging 18 weeks after implantation of PLA porous structures.

First, we evaluated the host-tissue reaction after implantation. Local inflammatory reaction assessed after implanting polymers can be divided into three main phases: acute ( $0-7$ days), subacute (7-28 days), and chronic ( $>28$ days). ${ }^{46}$ What is seen in general are polymorphonuclear leukocytes manifesting in early 

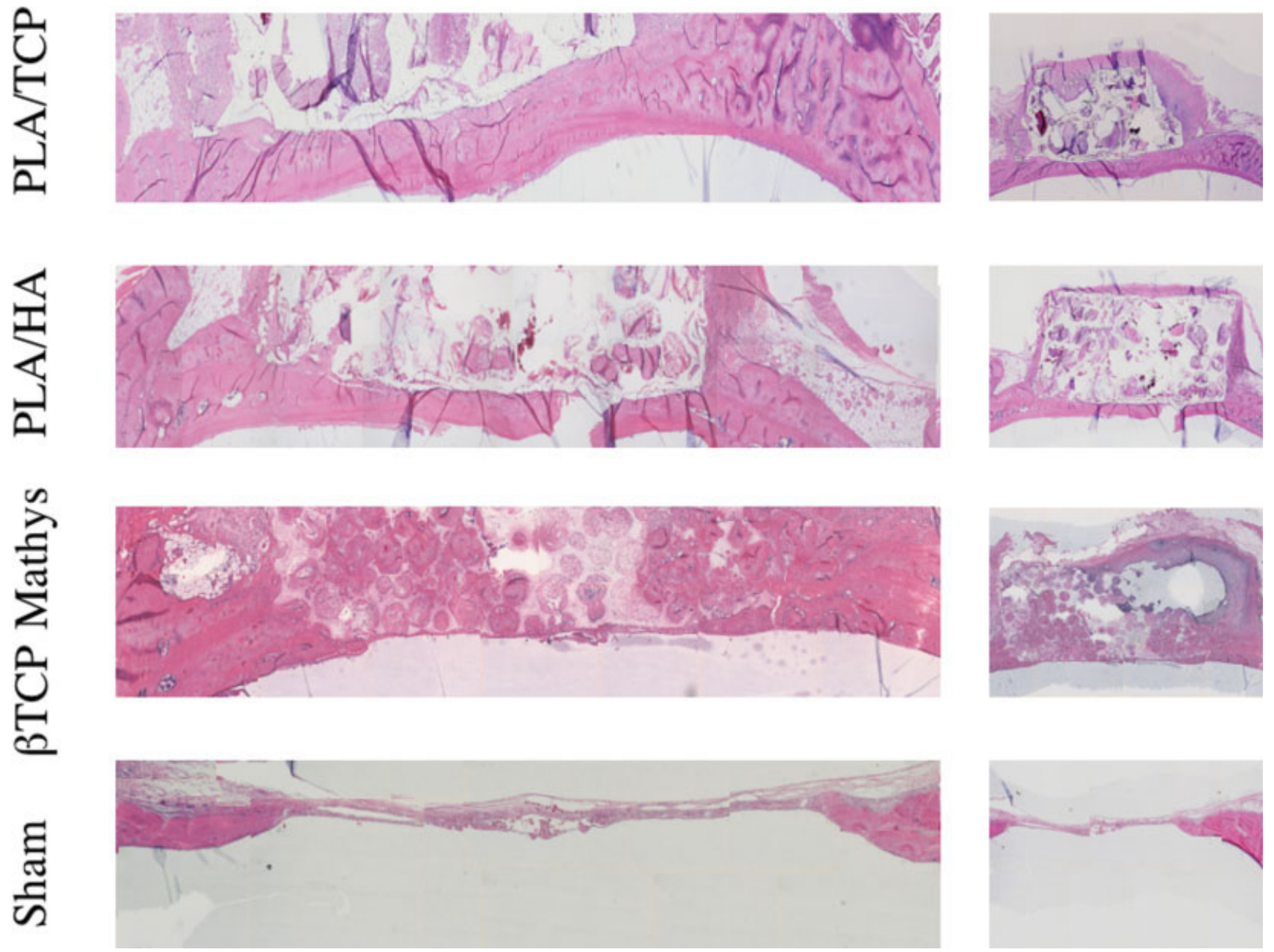

Figure 5. Histologic assessment of bone regeneration at 18 weeks. Three calvarial defects were analyzed for each group in $3 \mu \mathrm{m}$ sections stained with hematoxylin and eosin. Composite photomicrographs were assembled from histological sections closest to the center of the defects. Best healing responses are presented for each group: detailed cranial vaults (left) and general view of the implants (right). [Color figure can be viewed in the online issue, which is available at www. interscience.wiley.com.]

inflammation, attracted by chemokines released by damaged cells. ${ }^{48}$ In the subacute phase, monocytes, macrophages, and fibroblasts predominate, leading to the formation of a dense fibrous tissue, mainly consisting of fibroblasts and collagen matrix. ${ }^{49}$ The chronic phase is characterized by increased polymer degradation, few macrophages or giant cells, and fibrous encapsulation. ${ }^{50}$ Our observations are in accordance with these descriptions. In the present study, the host-tissue reaction was semiquantitatively evaluated, leading to similar results in the different treatment groups. Although highly reactive in all group tested, the response did regress with time to reach a moderate grade. This was principally due to the decreased fibrous capsule thickness and cellular content. The dense cell layer found 12 days after implantation could be due to the surgical trauma combined with an initial foreign body reaction. Systemic concentrations of IL6 and TNF- $\alpha$ were comparable with values reported in literature. ${ }^{51}$ Polymer resorption was apparent at the latest sacrifice, as fragments were observed within the new bone and the soft tissues but no sign of necrosis was noted.

Second, we characterized the ability of the structures to guide osteoprogenitor cells leading to new bone formation. Morphologically and embriologically, the calvaria develops from a membrane precursor and thus resembles the membranous bones of the face, whereas bones that form the base of the skull display endochondral ossification. Intramembranous ossification is characterized by the direct mineralization of a highly vascular connective tissue membrane. Analysis of the early events in the healing process indicates that new bone is generated mainly from the surface of the dura mater at the base of the defect, as well as from the periosteum 


\section{Sham}
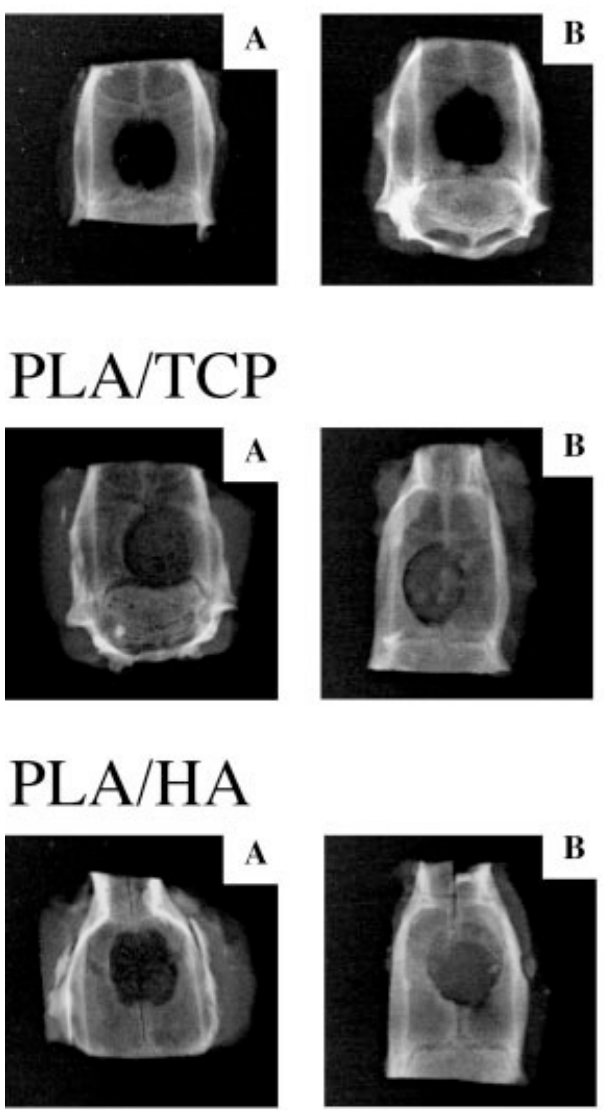

\section{$\beta T C P$ Mathys}
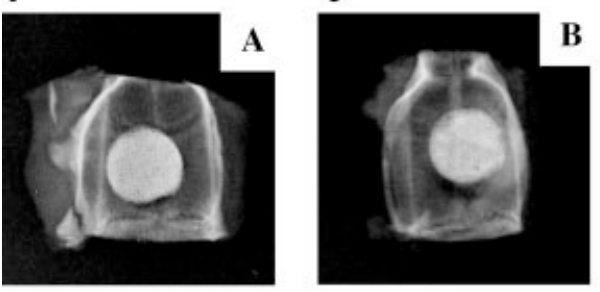
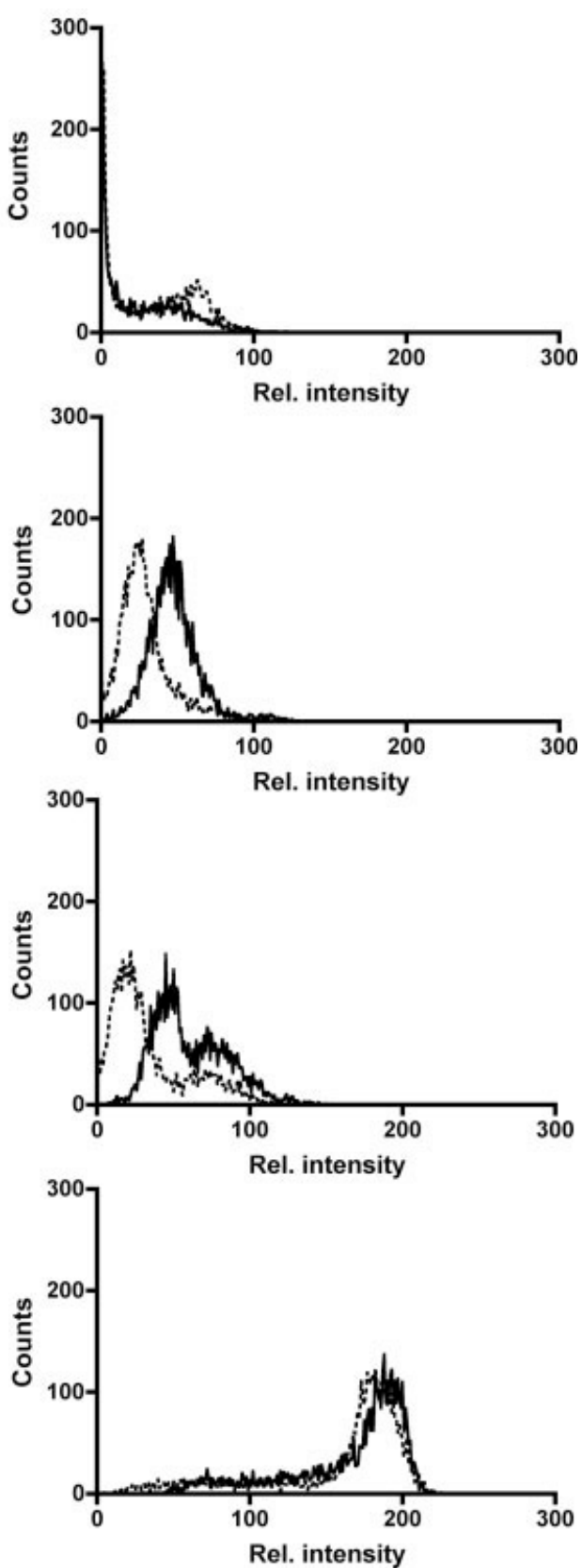

Figure 6. Roentgenograms of cranial trephine defects in adult rat skulls. The exocranial surfaces were exposed on top of a radiographic cassette (High Resolution Storage Phosphor Screen CR Cassette, Kodak, Rochester, NY) at a distance of $125 \mathrm{~cm}$ from the X-ray head $(10 \mathrm{mAs}, 50 \mathrm{kV})$. Samples were imaged and processed with an image analysis software (ImageJ, Wayne Rasband, National Institutes of Health, Bethesda, MD). Histograms of the defect area were generated from digitized radiographs with background adjusted to zero. X-rays were taken 12 days (A) and 18 weeks (B) after the surgical intervention. Representative images and corresponding histogram analyses are shown.

and perhaps-in a lesser measure-at the edges from the old bone. In this study, the thin trabeculae of the early bone were found to progress into a scattered network, which enclosed blood vessels forming primary osteonal systems. Corroborating these observations, trephine defects were shown to heal not only by ingrowth from the rim but also by proliferation of perivascular mesenchymal-type cells of the dura mater. ${ }^{24}$ In the first few days of bony healing, cells are migrating, attaching, and differentiating into osteoblasts to propagate bone growth. ${ }^{2}$ Thus, during this time, rigid fixation was important so that the stability of the implant can assure adequate control of experimental variables. In this preliminary study using only a small number of animals because of ethical reasons, we were able to appropriately choose time points and evaluation conditions. Even though the limitation of animal numbers did not allow statistical comparison of the X-ray data the values obtained were used to support the qualitative 
bone repair description in each implant group. Clear healing of the cranial defects treated with the PLA/ ceramic structures was observed by histology and confirmed by radiography.

\section{CONCLUSIONS}

The biocompatibility of PLA/ceramic foams was assessed in terms of inflammatory host response and fibrous capsule formation. Histological evaluation showed a marked but local and temporary restricted reaction. Moreover, the granulation tissue surrounding the implants was a foreign body reaction consisting mainly of macrophages, fibroblasts, and capillaries. No chronic inflammation was induced, as lymphocytes and eosinophils were rarely present in the close neighborhood of the constructs. The encountered FBGC were principally located around particulate materials detached from $\beta$-TCP scaffolds. Using shearing mechanical stimulations in vitro, PLA composites showed no apparent erosion due to their homogeneity, whereas pure $\beta$-TCP implants displayed scattered debris (data not shown). We conclude that PLA/ceramic architectures obtained by melt-extrusion coupled with supercritical gas foaming offer suitable conditions for host tissue integration. Furthermore, a complete reconstruction of the cranial vault was observed with the porous architecture of PLA/ceramic constructs. Thus, their osteoconductive properties previously described in vitro ${ }^{1}$ are confirmed in vivo as assessed by histology and radiography. On the basis of these promising results, further studies using the CSD craniotomy model with a larger sample size will be undertaken. Parallely, the same scaffolds will be integrated in long bones at the immediate vicinity of bone marrow and blood supply. This new approach to create composite structures is promising for tissue engineering, especially for applications in maxillofacial bone repair and during revision of total joint replacement.

The authors thank Veronique Garea from the Laboratoire de Médecine Régénérative et de Pharmacobiologie (EPFLLMRP) for excellent technical assistance, Sébastien Delaloye from the Hôpital Orthopédique de la Suisse Romande (HOSR-CHUV) for radiography, and the Centre Interdépartemental de Microscopie Electronique (EPFL-CIME) for SEM imaging. Dr. R. Mathys Foundation, Bettlach, Switzerland, kindly provided us with the $\beta$-TCP scaffolds.

\section{References}

1. Montjovent MO, Mathieu LM, Hinz B, Applegate LL, Bourban PE, Zambelli PY, Månson JAE, Pioletti DP. Biocompatibility of bioresorbable PLA composite scaffolds obtained by supercritical gas foaming with human fetal bone cells. Tissue Eng 2005;11:1640-1649.
2. Hollinger JO, Kleinschmidt JC. The critical size defect as an experimental model to test bone repair materials. J Craniofac Surg. 1990;1(1):60-68.

3. Schmitz JP, Hollinger JO. The critical size defect as an experimental model for craniomandibulofacial nonunions. Clin Orthop Relat Res 1986:299-308.

4. Prolo DJ, Pedrotti PW, Burres KP, Oklund S. Superior osteogenesis in transplanted allogeneic canine skull following chemical sterilization. Clin Orthop Relat Res 1982(168):230242.

5. Aalami OO, Nacamuli RP, Lenton KA, Cowan CM, Fang TD, Fong KD, Shi YY, Song HM, Sahar DE, Longaker MT. Applications of a mouse model of calvarial healing: Differences in regenerative abilities of juveniles and adults. Plast Reconstr Surg 2004;114:713-720.

6. Lee JY, Musgrave D, Pelinkovic D, Fukushima K, Cummins J, Usas A, Robbins P, Fu FH, Huard J. Effect of bone morphogenetic protein-2-expressing muscle-derived cells on healing of critical-sized bone defects in mice. J Bone Joint Surg Am 2001;83-A:1032-1039.

7. Mulliken JB, Glowacki J. Induced osteogenesis for repair and construction in the craniofacial region. Plast Reconstr Surg 1980;65:553-560.

8. Turnbull RS, Freeman E. Use of wounds in the parietal bone of the rat for evaluating bone marrow for grafting into periodontal defects. J Periodontal Res 1974;9:39-43.

9. Freeman E, Turnbull RS. The value of osseous coagulum as a graft material. J Periodontal Res 1973;8:229-236.

10. Ray RD, Holloway JA. Bone implants; preliminary report of an experimental study. J Bone Joint Surg Am 1957;39-A:11191128.

11. Frame JW. A convenient animal model for testing bone substitute materials. J Oral Surg 1980;38:176-180.

12. Kramer IR, Killey HC, Wright HC. A histological and radiological comparison of the healing of defects in the rabbit calvarium with and without implanted heterogeneous anorganic bone. Arch Oral Biol 1968;13:1095-1106.

13. Costantino PD, Friedman CD, Jones K, Chow LC, Sisson GA. Experimental hydroxyapatite cement cranioplasty. Plast Reconstr Surg 1992;90:174-185; discussion 186-191.

14. Friedenberg ZB, Lawrence RR. The regeneration of bone in defects of varying size. Surg Gynecol Obstet 1962;114:721726 .

15. Kuemmerle JM, Oberle A, Oechslin C, Bohner M, Frei C, Boecken I, von Rechenberg B. Assessment of the suitability of a new brushite calcium phosphate cement for cranioplastyAn experimental study in sheep. J Craniomaxillofac Surg 2005;33:37-44.

16. Viljanen VV, Gao TJ, Lindholm TC, Lindholm TS, Kommonen B. Xenogeneic moose (Alces alces) bone morphogenetic protein (mBMP)-induced repair of critical-size skull defects in sheep. Int J Oral Maxillofac Surg 1996;25:217-222.

17. Lindholm TC, Lindholm TS, Alitalo I, Urist MR. Bovine bone morphogenetic protein (bBMP) induced repair of skull trephine defects in sheep. Clin Orthop Relat Res 1988;227:265268.

18. Merkx MA, Maltha JC, Freihofer HP, Kuijpers-Jagtman AM. Incorporation of particulated bone implants in the facial skeleton. Biomaterials 1999;20:2029-2035.

19. Ripamonti U. Bone induction in nonhuman primates. An experimental study on the baboon. Clin Orthop Relat Res 1991(269):284-294.

20. Hollinger J, Mark DE, Bach DE, Reddi AH, Seyfer AE. Calvarial bone regeneration using osteogenin. J Oral Maxillofac Surg 1989;47:1182-1186; discussion 1187.

21. An YH, Friedman RJ. Animal models of bone defect repair. In: An YH, Friedman RJ, editors. Animal Models in Othopaedic Research. Boca Raton: CRC Press; 1999. p 241-260. 
22. Dahlin C, Alberius P, Linde A. Osteopromotion for cranioplasty. An experimental study in rats using a membrane technique. J Neurosurg 1991;74:487-491.

23. Glowacki J, Altobelli D, Mulliken JB. Fate of mineralized and demineralized osseous implants in cranial defects. Calcif Tissue Int 1981;33:71-76.

24. Takagi K, Urist MR. The reaction of the dura to bone morphogenetic protein (BMP) in repair of skull defects. Ann Surg 1982;196:100-109.

25. Laurencin CT, Lu HH. Polymer-ceramic composites for bonetissue engineering. In: Davies JE, editor. Bone Engineering; 2000. p 462-472.

26. Wang M. Developing bioactive composite materials for tissue replacement. Biomaterials 2003;24:2133-2151.

27. Maquet V, Boccaccini AR, Pravata L, Notingher I, Jerome R. Porous poly( $\alpha$-hydroxyacid)/Bioglass composite scaffolds for bone tissue engineering. I. Preparation and in vitro characterisation. Biomaterials 2004;25:4185-4194.

28. Mikos AG, Thorsen AJ, Czerwonka LA, Bao Y, Langer R. Preparation and characterization of poly(L-lactic acid) foams. Polymer 1994;35:1068-1077.

29. Thomson RC, Yaszemski MJ, Powers JM, Mikos AG. Hydroxyapatite fiber reinforced poly( $\alpha$-hydroxy ester) foams for bone regeneration. Biomaterials 1998;19:1935-1943.

30. Nam YS, Park TG. Porous biodegradable polymeric scaffolds prepared by thermally induced phase separation. J Biomed Mater Res 1999;47:8-17.

31. Whang K, Goldstick TK, Healy KE. A biodegradable polymer scaffold for delivery of osteotropic factors. Biomaterials 2000;21:2545-2551.

32. Lo H, Ponticiello MS, Leong KW. Fabrication of controlled release biodegradable foams by phase separation. Tissue Eng 1995;1:15-28.

33. Ma PX, Zhang R, Xiao G, Franceschi R. Engineering new bone tissue in vitro on highly porous poly $(\alpha$-hydroxyl acids)/hydroxyapatite composite scaffolds. J Biomed Mater Res 2001;54:284-293.

34. Hile DD, Amirpour ML, Akgerman A, Pishko MV. Active growth factor delivery from poly(D,L-lactide-co-glycolide) foams prepared in supercritical $\mathrm{CO}_{2}$. J Control Release 2000;66:177-185.

35. Howdle SM, Watson MS, Whitaker MJ, Popov VK, Davies MC, Mandel FS, Wang JD, Shakesheff KM. Supercritical fluid mixing: Preparation of thermally sensitive polymer composites containing bioactive materials. Chem Commun 2001;1: 109-110.

36. Watson MS, Whitaker MJ, Howdle SM, Shakesheff KM. Incorporation of proteins into polymer materials by a novel supercritical fluid processing method. Adv Mater 2002;14: 1802-1804.
37. Forman S, Kas J, Fini F, Steinberg M, Ruml T. The effect of different solvents on the ATP/ADP content and growth properties of HeLa cells. J Biochem Mol Toxicol 1999;13:11-15.

38. Mooney DJ, Baldwin DF, Suh NP, Vacanti JP, Langer R. Novel approach to fabricate porous sponges of poly(D,L-lacticco-glycolic acid) without the use of organic solvents. Biomaterials 1996;17:1417-1422.

39. Harris LD, Kim BS, Mooney DJ. Open pore biodegradable matrices formed with gas foaming. J Biomed Mater Res 1998;42:396-402.

40. Sheridan MH, Shea LD, Peters MC, Mooney DJ. Bioabsorbable polymer scaffolds for tissue engineering capable of sustained growth factor delivery. J Control Release 2000;64:91102.

41. Mathieu LM, Montjovent MO, Bourban PE, Pioletti DP, Månson JAE. Bioresorbable composites prepared by supercritical fluid foaming. J Biomed Mater Res A 2005;75:89-97.

42. Bohner M, Doebelin N, Baroud G. Theoretical and experimental approach to test the cohesion of calcium phosphate pastes. Eur Cell Mater 2006;12:26-35.

43. Mathieu L, Bourban P-E, Månson JAE. Processing of homogeneous ceramic/polymer blends for bioresorbable composites. Compos Sci Technol 2006;66:1606-1614.

44. Black J. In vivo implants models. Appendix 2: Rating system for tissue at animal implant sites. Biological Performance of Materials: Fundamentals of Biocompatibility. New York: Marcel Dekker; 1999. p 365.

45. Salthouse TN. Biologic response to sutures. Otolaryngol Head Neck Surg 1980;88:658-664.

46. Gourlay SJ, Rice RM, Hegyeli AF, Wade CW, Dillon JG, Jaffe $\mathrm{H}$, Kulkarni RK. Biocompatibility testing of polymers: In vivo implantation studies. J Biomed Mater Res 1978;12:219-232.

47. Sewell WR, Craver BN. The comparative antigenicity in the guinea pig of sutures from ovine submucosa and bovine serosa. Ann Surg 1955;142:980-985.

48. Woodward SC. Evaluation by light microscopy. In: Recum AFv, editor. Handbook of Biomaterials Evaluation. Philadelphia, PA: Taylor \& Francis; 1999. p 599-612.

49. Zislis T, Mark DE, Cerbas EL, Hollinger JO. Scanning electron microscopic study of cell attachment to biodegradable polymer implants. J Oral Implantol 1989;15:160-167.

50. Ibim SM, Uhrich KE, Bronson R, El-Amin SF, Langer RS, Laurencin CT. Poly(anhydride-co-imides): In vivo biocompatibility in a rat model. Biomaterials 1998;19:941-951.

51. Zingarelli B, Sheehan M, Hake PW, O'Connor M, Denenberg A, Cook JA. Peroxisome proliferator activator receptor$\gamma$ ligands, 15-deoxy- $\delta(12,14)$-prostaglandin $\mathrm{J} 2$ and ciglitazone, reduce systemic inflammation in polymicrobial sepsis by modulation of signal transduction pathways. J Immunol 2003; 171:6827-6837. 